\title{
Synchronous Primary Endometrial and Ovarian Cancers: A Critical Update
}

\section{Georgios Androutsopoulos* and Georgios Decavalas}

Department of Obstetrics and Gynecology, University of Patras, Medical School, Rion, Greece

\begin{abstract}
Synchronous primary cancers are relatively uncommon in general population [1,2]. Only $0.5-1.7 \%$ of women with gynecological malignancies, have synchronous primary cancers of the female genital tract [3-8]. In those patients, the most common combination is synchronous primary endometrial and ovarian cancers $[3,4,6]$
\end{abstract}

Patients with synchronous primary endometrial and ovarian cancers have distinct clinical characteristics including: young age, obesity, premenopausal status and nulliparity [9]. Usually, they are 10 - 20 years younger than patients with single endometrial or ovarian cancer $[4,10-13]$. The median age at diagnosis is 50 years $[3,8,9,11-15]$.

The pathogenesis of synchronous primary endometrial and ovarian cancers, remains unclear[2,6,16]. The theory of the secondary Müllerian system has been proposed to explain the development of synchronous primary cancers in the female genital tract [5,6,16-18] According to this theory, the epithelia of the upper female genital tract have common embryologic origin and respond as a morphologic unit to a carcinogenic stimulus (hormone, radiation, other) $[2,5,16$, 17]. Perhaps shared hormone receptors (estrogen receptors) are responsible for the development of synchronous primary cancers in the female genital tract $[5,6,18]$.

Moreover it is possible that those patients have a more fragile genome and prior genetic damage may predispose them to the development of synchronous primary cancers [16,19-23] Especially in patients with Lynch syndrome, there is a predisposition to multiple synchronous primary cancers (colon, endometrium, ovary, stomach, small bowel, ureter and renal pelvis) [24].

Thus embryologic, hormonal, genetic or other phenomena may be associated with the development of synchronous primary cancers of the female genital tract $[5,6,16-19,2124]$.

The most common presenting symptoms and signs in patients with synchronous primary endometrial and ovarian cancers, are: abnormal uterine bleeding (46\%), abdominal/pelvic pain (17\%) and abdominal/ pelvic mass (13\%) [1,2,9,11,13,15,16,25].

Synchronous primary endometrial and ovarian cancers may have similar or different histologic appearance $[6,10,14]$. The distinction between metastatic and synchronous primary cancers is relatively easy, when they have different histologic types [26,27] However the distinction is relatively difficult, when they have the same histologic type [26,27]. For those patients in clinical practise we use well described empirical criteria [26,27].

The treatment of choice for most patients with synchronous primary endometrial and ovarian cancers, is systematic surgical staging [1-4 $, 6,11,12,14,15,28-30]$. More specifically in those patients, systematic surgical staging includes: total abdominal hysterectomy with bilateral salpingo-oophorectomy, total omentectomy, appendectomy, pelvic and para-aortic lymphadenectomy, complete resection of all disease, biopsy of any suspected lesion and pelvic washings $[1,4,6,11,12,14$, 28-32].

That therapeutic approach allows a more clear decision for stage related postoperative adjuvant treatment $[1,2,29,30]$. Moreover,

\section{Publication History:}

Received: November 27, 2014

Accepted: January 27, 2015

Published: January 29, 2015

\section{Keywords:}

Synchronous primary cancers, Pathogenesis, Clinical characteristics, treatment, Prognosis

appropriate surgical staging facilitates targeted therapy that maximize survival and minimize the morbidity of overtreatment (radiation injury, chemotherapy toxicity) and the effects of undertreatment (recurrent disease, increased mortality) $[1,2,33]$.

Pelvic and para-aortic lymphadenectomy is essential for surgical staging in patients with synchronous primary endometrial and ovarian cancers $[1,2,31,32]$. It has diagnostic, therapeutic and prognostic value. It defines accurately the extent of disease and determines the prognosis of patients [1,2]. Undoubtedly, pelvic and para-aortic lymphadenectomy is the only way to identify patients with stage III disease $[1,2,31,32]$. However, the extension of pelvic and para-aortic lymph node dissection (more than 14 lymph nodes) is an independent risk factor for postoperative complications $[1,2,29,30,34-36]$ Moreover in elderly patients and in patients with relevant comorbidities (obesity, diabetes, coronary artery disease), morbidity must be carefully weighed against any survival advantage $[1,2,33,37,38]$.

The significance of postoperative adjuvant treatment in patients with synchronous primary endometrial and ovarian cancers, remains controversial [14,15,39]. However in most cases, postoperative adjuvant treatment should be individualized according to the risk of relapse of each primary cancer $[2,39,40]$ Moreover, the treatment of one primary cancer does not compromise the treatment of the other primary cancer $[2,41]$.

Especially in patients with advanced stage disease, unfavorable histologic types and high grade disease, required postoperative adjuvant treatment tailored to both tumors [1-3,6,10-12,15,25,28$30,39,41-43]$. More specifically, postoperative adjuvant treatment in those patients includes: radiotherapy and/or chemotherapy $[1,2,10,11$ 39].

Postoperative adjuvant radiotherapy includes: external pelvic radiotherapy and/or brachytherapy. It is the appropriate treatment for high risk primary endometrial cancer $[1,2,29,30]$.

"Corresponding Author: Dr. Georgios Androutsopoulos, Department of Obstetrics and Gynecology, University of Patras, Medical School, Rion 26504, Greece, Tel: +306974088092; E-mail: androutsopoulos@upatras.gr

Citation: Androutsopoulos G, Decavalas G (2015) Synchronous Primary Endometrial and Ovarian Cancers: A Critical Update. Int J Gynecol Clin Pract 2: 106. doi: http://dx.doi.org/10.15344/2394-4986/2015/106

Copyright: (c) 2015 Androutsopoulos et al. This is an open-access article distributed under the terms of the Creative Commons Attribution License, which permits unrestricted use, distribution, and reproduction in any medium, provided the original author and source are credited. 
Citation: Androutsopoulos G, Decavalas G (2015) Synchronous Primary Endometrial and Ovarian Cancers: A Critical Update. Int J Gynecol Clin Pract 2: 106. doi: http://dx.doi.org/10.15344/2394-4986/2015/106

Page 2 of 3

Postoperative adjuvant chemotherapy is the appropriate treatment for advanced stage primary endometrial and ovarian cancers $[1,2$ ,40]. The most active chemotherapeutic agents for those patients, are: taxanes, anthracyclines and platinum compounds $[11,15]$.

Prognostic factors for synchronous primary endometrial and ovarian cancers are: age, stage of ovarian cancer, grade of endometrial cancer and adjuvant treatment [43-45]. Patients with synchronous primary endometrial and ovarian cancers have 5 -year overall survival $85.9 \%$ and 10 year overall survival $80.3 \% .14$ Patients with synchronous primary endometrial and ovarian cancers have better overall survival than patients with single primary ovarian or endometrial cancer $[1,2,9,39,41,43,46]$. Moreover, patients with synchronous primary endometrial and ovarian cancers endometrioid type have better overall survival than patients with non-endometrioid or mixed histologic types $[1,2,9,39,43]$.

The reason for the better overall survival of those patients, is not intuitively obvious $[1,2,14]$. Perhaps favorable prognosis related with the detection of patients at early stage and low grade disease [1-3,6,20$22,25,28,46,47]$. Moreover, the influence of the postoperative adjuvant treatment needs to be further investigated [39].

\section{Competing Interests}

The authors declare that they have no competing interests.

\section{References}

1. Androutsopoulos G, Decavalas G (2013) Synchronous primary endometrial and ovarian cancers. J Community Med Health Educ 3: e120.

2. Androutsopoulos G, Decavalas G (2014) Synchronous primary endometria and ovarian cancers: pathogenesis, treatment and prognosis. Int $\mathrm{J}$ Clin Ther Diagn 2: 601.

3. Ayhan A, Yalçin OT, Tuncer ZS, Gürgan T, Küçükali T (1992) Synchronous primary malignancies of the female genital tract. Eur $\mathrm{J}$ Obstet Gynecol Reprod Biol 45: 63-66.

4. Tong SY, Lee YS, Park JS, Bae SN, Lee JM, et al. (2008) Clinical analysis of synchronous primary neoplasms of the female reproductive tract. Eur $J$ Obstet Gynecol Reprod Biol 136: 78-82.

5. Deligdisch L, Szulman AE (1975) Multiple and multifocal carcinomas in female genital organs and breast. Gynecol Oncol 3: 181-190.

6. Eisner RF, Nieberg RK, Berek JS (1989) Synchronous primary neoplasms of the female reproductive tract. Gynecol Oncol 33: 335-339.

7. Matlock DL, Salem FA, Charles EH, Savage EW (1982) Synchronous multiple primary neoplasms of the upper female genital tract. Gynecol Oncol 13: 271-277

8. Eser S, Gulhan I, Özdemir R, Dicle N, Hanhan M, et al. (2011) Synchronous primary cancers of the female reproductive tract in Turkish women. Asian Pac J Cancer Prev 12: 857-859.

9. Soliman PT, Slomovitz BM, Broaddus RR, Sun CC, Oh JC, et al. (2004) Synchronous primary cancers of the endometrium and ovary: a single institution review of 84 cases. Gynecol Oncol 94: 456-462.

10. Pearl ML, Johnston CM, Frank TS, Roberts JA (1993) Synchronous dual primary ovarian and endometrial carcinomas. Int J Gynaecol Obstet 43: 305-312.

11. Liu Y, Li J, Jin H, Lu Y, Lu X (2013) Clinicopathological characteristics of patients with synchronous primary endometrial and ovarian cancers: A review of 43 cases. Oncol Lett 5: 267-270.

12. Signorelli M, Fruscio R, Lissoni AA, Pirovano C, Perego P, et al. (2008) Synchronous early-stage endometrial and ovarian cancer. Int J Gynaecol Obstet 102: 34-38.
13. Rodolakis A, Thomakos N, Akrivos N, Sotiropoulou M, loannidis I, et al. (2012) Clinicopathologic insight of simultaneously detected primary endometrial and ovarian carcinomas. Arch Gynecol Obstet 285: 817-821.

14. Zaino R, Whitney C, Brady MF, DeGeest K, Burger RA, et al. (2001) Simultaneously detected endometrial and ovarian carcinomas--a prospective clinicopathologic study of 74 cases: a gynecologic oncology group study. Gynecol Oncol 83: 355-362.

15. Chiang YC, Chen CA, Huang CY, Hsieh CY, Cheng WF (2008) Synchronous primary cancers of the endometrium and ovary. Int $\mathrm{J}$ Gynecol Cancer 18: 159-164

16. Woodruff JD, Solomon D, Sullivant $H$ (1985) Multifocal disease in the upper genital canal. Obstet Gynecol 65: 695-698.

17. Lauchlan SC (1972) The secondary Müllerian system. Obstet Gynecol Surv 27: $133-146$.

18. Sica V, Nola E, Contieri E, Bova R, Masucci MT, et al. (1984) Estradiol and progesterone receptors in malignant gastrointestinal tumors. Cancer Res 44: $4670-4674$

19. Herrinton LJ, Voigt LF, Weiss NS, Beresford SA, Wingo PA (2001) Risk factors for synchronous primary endometrial and ovarian cancers. Ann Epidemiol 11: 529-533

20. Terzakis E, Androutsopoulos G, Grigoriadis C, Zygouris D, Derdelis G, et al. (2010) Synchronous primary endometrial and fallopian tube cancers. Eur J Gynaecol Oncol 31: 467-468.

21. Androutsopoulos G, Adonakis G, Tsamantas A, Liosis S, Antonopoulos A, et al. (2008) Synchronous primary cancers in a woman with scleroderma: a case report. Eur J Gynaecol Oncol 29: 548-550.

22. Decavalas G, Adonakis G, Androutsopoulos G, Gkogkos P, Koumoundourou D, et al. (2006) Synchronous primary endometrial and ovarian cancers: a case report. Eur J Gynaecol Oncol 27: 434-436.

23. Grigoriadis C, Androutsopoulos G, Zygouris D, Arnogiannaki N, Terzakis E (2012) Synchronous squamous cell carcinoma of the endometrium and endometrioid adenocarcinoma of the ovary. Eur J Gynaecol Oncol 33: 666668 .

24. Lynch HT, Smyrk T (1996) Hereditary nonpolyposis colorectal cancer (Lynch syndrome). An updated review. Cancer 78: 1149-1167.

25. Sheu BC, Lin HH, Chen CK, Chao KH, Shun CT, et al. (1995) Synchronous primary carcinomas of the endometrium and ovary. Int J Gynaecol Obstet 51: $141-146$

26. Ulbright TM, Roth LM (1985) Metastatic and independent cancers of the endometrium and ovary: a clinicopathologic study of 34 cases. Hum Pathol 16: $28-34$.

27. Scully R, Young R, Clement $P$ (1988) Tumors of the ovary, maldeveloped gonads, fallopian tube, and broad ligament. In: Armed Forces Institute of Pathology/American Registry of Pathology WD, editor. Atlas of Tumor Pathology.

28. Androutsopoulos G, Adonakis G, Tsamandas A, Andonopoulos A, Decavalas G (2011) Systemic Sclerosis and Multiple Cancers of the Female Genital Tract: Prolonged Survival following Current Treatment Strategies. Case Rep Rheumatol 2011: 392068.

29. Androutsopoulos G, Decavalas G (2013) Management of endometrial cancer. Int J Trans Commun Med 1: 101.

30. Androutsopoulos G (2012) Current treatment options in patients with endometrial cancer. J Community Med Health Educ 2: e113.

31. Prat J; FIGO Committee on Gynecologic Oncology (2014) Staging classification for cancer of the ovary, fallopian tube, and peritoneum. Int $\mathrm{J}$ Gynaecol Obstet 124: 1-5.

32. Pecorelli S (2009) Revised FIGO staging for carcinoma of the vulva, cervix, and endometrium. Int J Gynaecol Obstet 105: 103-104. 
Citation: Androutsopoulos G, Decavalas G (2015) Synchronous Primary Endometrial and Ovarian Cancers: A Critical Update. Int J Gynecol Clin Pract 2: 106. doi: http://dx.doi.org/10.15344/2394-4986/2015/106

33. American College of Obstetricians and Gynecologists (2005) ACOG practice bulletin, clinical management guidelines for obstetriciangynecologists, number 65, August 2005: management of endometrial cancer. Obstet Gynecol 106: 413-425.

34. Benedetti Panici P, Basile S, Maneschi F, Alberto Lissoni A, Signorelli M, et al. (2008) Systematic pelvic lymphadenectomy vs. no lymphadenectomy in early-stage endometrial carcinoma: randomized clinical trial. J Natl Cancer Inst 100: 1707-1716.

35. Franchi M, Ghezzi F, Riva C, Miglierina M, Buttarelli M, et al. (2001) Postoperative complications after pelvic lymphadenectomy for the surgical staging of endometrial cancer. J Surg Oncol 78: 232-237.

36. May K, Bryant A, Dickinson HO, Kehoe S, Morrison J (2010) Lymphadenectomy for the management of endometrial cancer. Cochrane Database Syst Rev : CD007585.

37. Lachance JA, Darus CJ, Rice LW (2008) Surgical management and postoperative treatment of endometrial carcinoma. Rev Obstet Gynecol 1: 97-105.

38. Lowery WJ, Gehrig PA, Ko E, Secord AA, Chino J, et al. (2012) Surgical staging for endometrial cancer in the elderly - is there a role for lymphadenectomy? Gynecol Oncol 126: 12-15.

39. Ma S, Zhang H, Sun $Y$, Wu L (2009) Synchronous primary cancers of the endometrium and ovary: review of 43 cases. Chinese-German J Clin Onco 8: 95-99.

40. Heitz F, Amant F, Fotopoulou C, Battista MJ, Wimberger P, et al. (2014) Synchronous ovarian and endometrial cancer--an international multicenter case-control study. Int J Gynecol Cancer 24: 54-60.

41. Castro IM, Connell PP, Waggoner S, Rotmensch J, Mundt AJ (2000) Synchronous ovarian and endometrial malignancies. Am J Clin Oncol 23 521-525.

42. Eifel P, Hendrickson M, Ross J, Ballon S, Martinez A, et al. (1982) Simultaneous presentation of carcinoma involving the ovary and the uterine corpus. Cancer 50: 163-170.

43. Lim YK, Padma R, Foo L, Chia YN, Yam P, et al. (2011) Survival outcome of women with synchronous cancers of endometrium and ovary: a 10 year retrospective cohort study. J Gynecol Oncol 22: 239-243.

44. Ayhan A, Guvenal T, Coskun F, Basaran M, Salman MC (2003) Survival and prognostic factors in patients with synchronous ovarian and endometria cancers and endometrial cancers metastatic to the ovaries. Eur J Gynaecol Oncol 24: 171-174.

45. Song T, Seong SJ, Bae DS, Kim JH, Suh DH, et al. (2014) Prognostic factors in women with synchronous endometrial and ovarian cancers. Int $J$ Gynecol Cancer 24: 520-527.

46. Williams MG, Bandera EV, Demissie K, Rodríguez-Rodríguez L (2009) Synchronous primary ovarian and endometrial cancers: a populationbased assessment of survival. Obstet Gynecol 113: 783-789.

47. van Altena AM, Geels YP, Bulten J, Kiemeney LA, de Hullu JA, et al. (2012) Why do women with double primary carcinoma of the endometrium and ovary have a favorable prognosis? Int J Gynecol Pathol 31: 344-351. 